\title{
W OU A INVENÇÃO DA MEMÓRIA COMO INSCRIÇÃO DO SUJEITO
}

\author{
W OR THE INVENTION OF MEMORY \\ AS AN INSCRIPTION OF THE SUBJECT \\ Rodrigo lelpo \\ Universidade Federal do Rio de Janeiro \\ Rio de Janeiro \\ Brasil
}

Ce n'est pas le passé qui nous domine.

Ce sont les images du passé.

GEORGE STEINER

\section{Resumo}

Em 1975, Georges Perec publica Wou le souvenir d'enfance, obra ao mesmo tempo ficcional e autobiográfica, na qual dois regimes diferentes de enunciação aparecem lado a lado. Em seu livro, Perec coloca em cena esse indecidível entre o imperativo de narrar o que ele não viveu e sua impossibilidade absoluta, desenvolvendo uma estratégia narrativa na qual, através da ficção, ele procura enfrentar sua falta de lembranças. $\mathrm{O}$ objetivo deste artigo é analisar o modo como esses dois regimes operam, permitindo a criação de um espaço duplo em que autor e narrador não cessam de se confundir em um jogo em que o sujeito só pode existir sob o risco de sua completa dissolução. Palavras-chave: Perec; memória; cinzas; desaparecimento.

\section{Abstract}

In 1975, Georges Perec published Wou le souvenir d'enfance, a work that is both fictional and autobiographical, and in which there are two different systems of enunciation side by side. In his book, Perec shows this undecidability between the imperative of narrating that which he hasn't lived and the complete impossibility of such narrative. By developing a narration strategy based on a certain use of fiction, Perec tries to face his lack of memories. This paper aims at analyzing how these two systems operate in order to create a double space where author and narrator get mixed up, creating a game

\section{Resume}

En 1975, Georges Perec fait publier Wou le souvenir d'enfance, œuvre à la fois fictionnelle et autobiographique où deux régimes différents d'énonciation sont mis côte à côte. Dans ce texte, Perec met en scène cet indécidable entre l'impératif de narrer ce qu'il n'a pas vécu et son impossibilité absolue, développant une stratégie narrative où, à travers la fiction, il essaie de faire face à l'expérience de son manque de souvenirs. Le but de cet article est d'analyser la façon dont ces deux régimes opèrent pour permettre la création de cet espace double où l'auteur et le narrateur ne cessent de se confondre

\footnotetext{
${ }^{1}$ Essa citação aparece como epígrafe de Le tombeau d'Alexandre, filme de Chris Marker.
} 
in which the subject can only exist at the risk of his complete dissolution.

Keywords: Perec; memory; ashes; disappearance. dans un jeu où le sujet ne peut exister qu'au risque de sa complète dissolution. Mots-clés: Perec; mémoire; cendres; disparition.

Em Face à l'immémorable, o escritor Louis-René Des Forêts desarma a oposição habitual que sustentaria as relaçóes entre memória e ficção ao fazer a seguinte afirmação diante do apagamento das lembranças:

A imaginação que vem ulteriormente cobrir a perda, longe de atentar contra a verdade íntima do ser, não faz senão desvelá-la melhor, daí, se tal é o fim buscado, a oportunidade que representa, às vezes, o seu auxílio, estando a distinção entre o falso e o autêntico como apagada, prova de que eles se anulam ou coexistem harmoniosamente. (DES FORETS, 1993: 20-21)²

Segundo o comentário de Des Forêts, a imaginação não seria o que afasta a verdade do ser, mas justamente aquilo que possibilitaria um melhor acesso a ela. Essa reflexão nos permite pensar um tipo de produção autobiográfica na qual se insere $W$ ou le souvenir d'enfance, romance de Georges Perec constituído por duas narrativas que se entrecruzam, alternando ficção e autobiografia. ${ }^{3}$ Todavia, apesar dessa alternância, a parte dita fictícia de $W$ não cessa de nos remeter a questóes diretamente ligadas à vida do autor: uma máe desaparecida, um órfáo e seu duplo, uma ilha onde o esporte impóe a seus cidadãos uma higiene de vida que não difere muito da que era imposta aos prisioneiros dos campos de concentração. História inacabada, essa parte do texto se impóe ao leitor como chave interpretativa, oferecendo certa inteligibilidade ao segmento autobiográfico.

A formulação dessa dinâmica pode ser pensada a partir de uma série de artigos que Perec escreveu entre 1959 e 1963 para um projeto de revista chamado La Ligne Générale. Embora a revista jamais tenha sido publicada, ${ }^{4} \mathrm{o}$ conjunto de textos escritos pelo escritor expóe, de maneira geral, um discurso crítico em relação à produção literária francesa do mesmo período. Os anos do pós-guerra aparecem como ponto de partida para sua reflexão, fato que náo deve nos surpreender, tendo em vista sua condição de filho de imigrantes judeus vindos da Polônia, e cujos destinos foram diretamente condicionados pelo horror da Segunda Guerra Mundial. Seu pai foi morto em combate, lutando entre os soldados da Legiáo Estrangeira, em defesa da França,

\footnotetext{
${ }^{2}$ Todas as traduçôes dos textos estrangeiros citados neste artigo são de minha autoria.

${ }^{3}$ PEREC, 2002.

${ }^{4}$ No início dos anos 1990, os artigos que Perec havia escrito para a revista foram publicados na forma de uma antologia intitulada $L G$. PEREC, 1992.
} 
enquanto sua mãe desapareceu após ter sida transferida de um campo de concentração em Drancy, próximo a Paris, para Auschwitz.

É possível notar, já nos artigos para $L G$, as pistas de uma tomada de posição que apontavam para a importância "estrutural" do discurso literário na constituição das memórias, indicando uma postura que vai encontrar seu pleno desenvolvimento durante a participação de Perec junto ao grupo OuLiPo. ${ }^{5}$ Como exemplo maior dessa posição nesses anos iniciais, podemos citar os comentários do jovem escritor em relação ao livro L'espèce humaine, ${ }^{6}$ escrito por Robert Antelme após sua experiência como prisioneiro político em um campo de concentração. Em "Robert Antelme ou la vérité de la littérature", ao analisar o testemunho de Antelme, Perec faz o elogio do que considera ser uma estética que tenta dar conta da realidade, sem, no entanto, tornar-se presa do que ele irá chamar de "ideais objetivistas do naturalismo". Segundo Perec, a recusa do ex-preso, em seu relato, em recorrer a um tom hiperbólico ou apocalítico,

participa de uma vontade deliberada que governa a organização de sua narrativa mesmo em seus menores detalhes, dando-lhe sua coloração específica: uma simplicidade, uma cotidianidade até então desconhecida, e que chega a trair a realidade a fim de exprimi-la de maneira mais eficaz (...). (PEREC, 94)

Na passagem acima, é preciso destacar a noção de "eficácia da expressão", ligada à própria estrutura de W ou le souvenir d'enfance. Ao analisarmos com atenção o fragmento citado, podemos perceber que, para Perec, exprimir o real de forma eficaz demandaria, antes de tudo, um ato de "traição" em relação àquilo de que falamos. É esse gesto que terá enorme importância na estruturação de $W$. Em uma espécie de manual de leitura publicado na contracapa da edição francesa, Perec explica que as duas partes que compóem o livro estão completamente ligadas, e que é preciso pensar no conjunto desses textos como se "dessa luz longínqua que lançam um sobre o outro, pudesse se revelar o que jamais é totalmente dito em um, jamais totalmente dito no outro, mas somente em sua frágil intercessão" (PEREC, 1975). ${ }^{8}$ Retomando as palavras de Des Forêts citadas mais acima, compreendemos melhor o papel da ficção na narrativa de Perec: ao invés de afastar o ser de sua verdade, o fictício traça o caminho que lhe permite encontrá-la. De maneira um tanto oblíqua, é um pouco o que nos diz Amaury Conson, personagem de La disparition,

\footnotetext{
${ }^{5}$ Ouvroir de Littérature Potentielle.

${ }^{6}$ ANTELME, 1978.

${ }^{7} \mathrm{O}$ grifo é meu.

8 “(...) dessa luz longínqua que lançam um sobre o outro, pudesse se revelar o que jamais é totalmente dito num, jamais totalmente dito no outro, mas somente em sua frágil interseçáo.”
} 
outro romance do autor. Ao falar do mistério concernente à morte de um dos personagens da narrativa, Conson faz a seguinte afirmação: “(...) li um bom trecho, possivelmente próximo do conjunto todo, do testemunho de Enton Vogl. Nestes escritos, ele refere cinco ou seis vezes um livro em que, pode ser, encontremos o fim do mistério" (PEREC, 2002: 393). ${ }^{9}$ Como no caso de $W$, vida e ficção aparecem nessa passagem ligadas em uma espécie de mise en abyme que opera sobre a formação de sentido do próprio romance, indicando ao leitor esse entrelaçamento essencial da trama autobiográfica perecquiana. Para falar do desaparecimento que marca a ausência de seus pais, Perec compóe um díptico intitulado $W$, no qual atletas encerrados em um campo de "treinamento" que mais parece campo de concentração vêm, de tempos em tempos, se interpor à descrição objetiva de alguns traços da vida do autor.

Esse cruzamento entre os dois textos é que permite ao escritor escapar do que seria uma oposição entre verdadeiro/memória e falso/ficção, problematizando a constituição da própria memória e os processos de montagem que estariam ligados à sua produção. Em "La fiction de la mémoire", Jacques Rancière descreve um dispositivo que nos permite uma melhor compreensão dessa problemática em $W$. Em seu artigo, Ranciére analisa o efeito de montagem no filme Le tombeau d'Alexandre, de Chris Marker. Ao estudar esse procedimento tal como utilizado pelo cineasta, o filósofo nos diz que "uma memória é um certo conjunto, um certo arranjo de signos, de traços, de monumentos" (RANCIÈRE, 1999: 36-47). Texto em que dois regimes de enunciação são dispostos lado a lado para a melhor "eficácia" do conjunto narrativo, $W$ dramatizaria, através do "arranjo" produzido por Perec, aquilo que seria um indecidível entre o imperativo de narrar a experiência da guerra, vivida através do destino de seus pais, e sua impossibilidade. É nesse sentido que parece agir a escolha deliberada do autor em cruzar as duas histórias do livro, criando, assim, um mecanismo que permite uma reverberação oblíqua do horror vivido pelos "atletas" da ilha W sobre as descrições aparentemente neutras de determinados momentos de sua vida. Poderíamos falar aqui de uma experiência das cinzas, segundo as reflexôes que Jacques Derrida desenvolve em "Il n'y a pas de narcissisme":

(...) "cinza" diz melhor o que gostaria de dizer sob o nome de traço, a saber, qualquer coisa que resta sem restar. Que não é nem presente nem ausente; que se destrói ele mesmo, a si mesmo, que se consome totalmente, que é um resto sem resto. Quer dizer, alguma coisa que não é (...). A cinza não é! A cinza não é, isso significa que ela testemunha sem testemunhar. Ela testemunha sobre o

\footnotetext{
${ }^{9}$ La disparition é um lipograma de mais de trezentas páginas escritas sem a letra "e", marca do feminino e desinência dos verbos de primeiro grupo em francês. Na tradução acima, procuramos manter o jogo do original, suprimindo a letra "a”. No original: «(...) j’ai lu un bon bout, sinon la plupart du Journal d'Anton Voyl. Il y fait cinq ou six fois allusion à un roman qui, dit-il, fournirait la solution».
} 
desaparecimento da testemunha, pode-se dizer. Ela testemunha sobre o desaparecimento da memória. (DERRIDA, 1992: 222)

$\mathrm{O}$ arranjo textual proposto por Perec tenta justamente fazer frente às desapariçóes indicadas por Derrida. Em W, A ficção permite a criação desse espaço duplo, no qual autor, narrador e herói não cessam de se confundir em um jogo em que o sujeito - objeto do narrado - joga sua existência sob o risco de seu completo desaparecimento. O traço escrito só é possível a partir das cinzas, ao mesmo tempo em que também encena o movimento e incineração que ameaçam apagar todo rastro a cada nova inscrição. De certa forma, essa dinâmica pode ser esclarecida no momento em que o narrador de $W$ "confessa" a seu leitor os motivos que mobilizam sua escritura: “(...) escrevo porque eles deixaram em mim suas marcas indeléveis e o traço destas é a escritura: suas lembranças estão mortas para a escritura: a escritura e a lembrança de suas mortes é a afirmação da minha vida" (PEREC, 1975: 63-64). Traço, morte, escrita e lembrança: aspectos dessa poética em que a angústia do branco comanda o escurecimento da página, em que o apagamento dos rastros engendra o trabalho da memória por meio do registro (impossível?) das cinzas.

As relaçóes apontadas acima são abordadas por Derrida em diversos textos, dentre os quais seria interessante destacar "Freud et la scène de l'écriture" (DERRIDA, 1967: 293-340). Ao comentar o percurso teórico de Freud através de textos como "Esquisse d'une psychologie scientifique", "L'interprétation des rêves" e "Note sur le bloc magique", Derrida faz, ao mesmo tempo, o elogio e a crítica da concepção freudiana de memória. Se, por um lado, o filósofo franco-argelino procura aprofundar a metáfora freudiana do psiquismo como uma máquina de escrever, demonstrando em sua leitura do discurso psicanalítico como essa metáfora opera, por outro, ele critica o uso feito por Freud da noção de tradução, ligada a de interpretação, "segundo a qual a ideia de presença torna-se evidente por meio da fixidez de um sentido na tradução.” (BIRMAN, 2007/1 n. 15: 215). Retomando a própria reflexão de Freud, Derrida procura desconstruir essa ideia de um sentido estabilizado, central, isolando, para isso, os momentos em que a metáfora da máquina de escrever aparece nos textos do psicanalista alemáo. Ao fazê-lo, Derrida empreende o passo a mais que Freud não arrisca, afirmando que,

Os traços não produzem, portanto, o espaço da sua inscrição senão se dando ao período do seu apagamento. Desde a origem, no "presente" da sua primeira impressão, são constituídos pela dupla força de repetição e de apagamento, de legibilidade e de ilegibilidade. (DERRIDA, 1967: 334)

Ecoando essas tensóes entre repetição e apagamento, legibilidade e ilegibilidade, o texto de Perec coloca em jogo biografemas (in)formados pela montagem textual que lhe conferem uma unidade narrativa. As implicaçóes desse 
gesto são de ordem ética, apontando para o fato de que o sentido dos traços com os quais jogamos não pode ser decidido anteriormente ao próprio lance da escritura. De onde poderíamos concluir que a ficcionalizaçáo é o princípio de montagem que permite ao escritor participar ativamente da construção de sua memória, sem, entretanto, forçar os signos a significaçóes que já estariam dadas de antemão, esperando apenas mão do escriba para traduzi -las. Se aceitarmos a lógica proposta por Derrida, se há, de fato, uma revelação a ser descoberta, ela não depende em menor medida de um processo de criação, pois "O post-scriptum que constitui o presente passado como tal não se contenta, como talvez tenham pensado Platáo, Hegel e Proust, em despertá-lo ou revelá-lo na sua verdade. Ele o produz" (DERRIDA, 1967: 317).

Reverberando as palavras de Des Forêts, o comentário de Derrida evoca, novamente, as relações entre memória e ficção, indicando o caráter de produtividade que estaria ligado à criação das lembranças. E esse parece ser o partido tomado por Perec em $W$, ao fazer da parte dita fictícia um elemento central do maquinário autobiográfico colocado em movimento pelo autor. Logo no primeiro capítulo do livro, ao final de uma pequena introdução sobre a história que nos será contada, o narrador faz a seguinte afirmação: "no testemunho que me disponho a dar, fui testemunha, e não ator. Não sou o herói de minha história. Também não sou seu cantor" (PEREC, 1975: 14). Perec não era, certamente, um sobrevivente no sentido estrito do termo, mas descendia diretamente de uma geração que havia retornado (ou não) dos campos de concentração. Colocando-se, então, no lugar daquele que não havia sido enredado pelos fatos descritos, e, mais que isso, que não havia nem mesmo estado "presente" à história contada, o autor precisa criar um dispositivo textual que construa a voz desse testemunho possível, fazendo da própria ausência uma espécie de figura maior de pertencimento ao narrado. É, provavelmente, durante uma entrevista sobre o filme Récits d'Ellis Island que a complexidade dessa relação aparece de forma mais explícita, sob o modo de um imperativo ético na construção de uma memória coletiva. Realizado a partir de uma parceria de Perec com o diretor Robert Bober, o filme fala da chegada dos judeus a Nova Iorque até a metade dos anos 1940, ou seja, logo após o final da guerra. Em certo momento dessa entrevista, o escritor tenta precisar a ideia que Bober e ele faziam do filme que estavam fazendo:

(...) vamos fazer um filme que será uma evocaçáo desse movimento que nem Robert, nem eu conhecemos (já que permanecemos na França), mas que poderíamos ter conhecido, que estava de alguma maneira inscrito em nosso possível (...). É, portanto, um trabalho sobre a memória, e sobre uma memória que nos concerne, ainda que não seja a nossa, mas que está, como dizer... ao lado da nossa, e que nos determina quase tanto quanto a nossa história. (PEREC, 2003: 50) 
É preciso notar a relação entre história e memória que Perec tece nesse comentário. Ao permitir que sua história pessoal se imbrique nas cinzas dessa memória coletiva, o autor se inscreve como personagem desse grande destino judeu, ainda que ele tenha permanecido na França, distante de todo esse movimento de imigração. O que está em jogo nessa relação aparece no próprio texto de Ellis Island sob o nome de "memória potencial": "(...) longe de nós no tempo e no espaço, esse lugar faz para a gente parte de uma memória potencial, de uma autobiografia provável" (PEREC, 1995: 56). Em um cotejamento com as questóes apontadas em $W$, pode-se afirmar que o termo "provável" remete a um futuro sob a forma de uma construçáo desse devir judeu, o qual, por sua vez, estaria ligado à própria falta de memória de um passado que o configuraria, como evocado pelo narrador da parte autobiográfica do livro: "[e]u não tenho memórias de infância" (PEREC, 1975: 13). É a partir dessa ruptura na narrativa de uma história pessoal em função da violência da guerra que é preciso narrar: "(...) une autre histoire, la grande, l'Histoire avec sa grande hache, avait déjà répondu à ma place: la guerre, les camps.” ““[...] uma outra história, a grande, a História com seu grande machado, já havia respondido em meu lugar: a guerra, os campos.") (PEREC, 1975: 13. No idioma original, a brincadeira com o uso do vocábulo hache, machado e nome da letra "h", com a qual se inicia a palavra Histoire, permite o jogo de palavras com que Perec coloca em evidência toda a complexidade que existe, segundo ele, entre sua história pessoal e aquela dos grandes eventos. Como falar de si se a existência foi ceifada por esse grande machado (hache) da história? ${ }^{10}$ A figura do desaparecimento funcionaria, então, como importante móbile da escritura desenvolvida por Perec, não só em $W$, mas em outras obras importantes como La vie mode d'emploi e La disparition, remetendo-nos ao sentimento descrito pelo escritor em outra de suas entrevistas: "(c)omo se eu não escrevesse, isso fosse desaparecer completamente (...)” (PEREC, 2003: 190). Escrever seria, assim, perpetuar os traços que tecem o próprio destino do escritor, diferindo-os para que eles possam continuar a significar, para que ele, Perec, não desapareça. Retomando o diálogo com Derrida, parece oportuno pensar aqui no comentário feito por Marc Crépon em seu artigo "Sigmund parle-t-il en Derrida?”: "Aquilo que chamamos 'cultura' não é um trabalho de si sobre si, como se diz às vezes de forma apressada, mas um trabalho do outro sobre si - uma hospitalidade ameaçadora porque ela produz afastamento, diferença, perda (...)" (CREPON, 2014: 58).

\footnotetext{
${ }^{10}$ Para um maior aprofundamento dessas relaçôes, ver MOLKOU, Elizabeth; ROBIN, Régine: "De l'arbre à l'herbier. L'histoire pulvérisée». In: Georges Perec et l'histoire. Copenhague: Mueseum Tusculanum Press et les auteurs, 2000: 87-104.
} 
O traço como cinza indicaria aqui esse duplo risco de desaparecimento: seja pelo apagamento dos rastros - de uma cultura -, seja pelo próprio desaparecimento do sujeito fantasmagorizado pela figura do outro. Todavia, essa aparente aporia funciona, na verdade, como força motriz da poética da memória encenada em $W$, na qual o sujeito não é constituído em um tempo anterior à escritura. Traçar é inscrever seu próprio destino, inserindo-se, assim, em uma cultura que náo cessa de modificar aquele que escreve, menos para fazê-lo desaparecer que para permiti-lo existir. Em $W$, a verdade íntima do sujeito não se encontra em um passado acabado, pronto para ser desvelado, mas em cada traço de seu texto, como testemunha a confusão aí encontrada entre autor, narrador e herói.

Inscrevendo seus biografemas assim como os de sua família sobre a página branca, Perec escreve a si próprio por meio das cinzas, recriando-se em uma economia significante em que a ficção lhe permite dar sentido a uma memória que só pode existir se trabalhada pelo presente: inscriçẫo e apagamento, vida e morte: essas são as forças que comandam a lógica dessa escritura-cinza que não para de abrir vozes e vias para que o sujeito não desapareça em meio aos "vestígios subterrâneos de um mundo que ele acreditava ter esquecido” (PEREC, 1975: 220), como nos diz o narrador da parte fictícia de $W$. Vestígios que compõem uma memória a partir de lembranças que o próprio Perec jamais teve: "pilhas de dentes de ouro, alianças, óculos, milhares e milhares de roupas amontoadas, fichários empoeirados, estoques de sabão de má qualidade..." (ibidem).

A ficção é o que permite a Perec essa arte da montagem em que o autor rearranja os traços sob a forma de narrativa. É assim que, segundo Georges Didi-Huberman, "as 'brancas preocupaçóes' de Georges Perec tornam-se, então, solicitaçóes à escrita apesar de tudo, solicitação em direção ao témoignaire, ${ }^{11}$ interlocutor ou leitor" (DIDI-HUBERMAN, 2013: 104). A enumeração dos objetos acima citados surgem como índices de um desaparecimento, remetendo o leitor a essa falta que se constitui enquanto presença em diversos momentos de $W$, enunciando, assim, aquilo que não está lá, mas também aquilo que poderia aí se encontrar. Trabalhando o espaço da página em branco, a ausência deixa de se referir apenas a um passado perdido, indicando, a partir de então, as potências imaginativas dessa "memória potencial" que pode, por meio da ficção, prestar contas de uma vida que continua a se inscrever.

$\mathrm{Na}$ parte final do livro, no momento em que nos confidencia os autores de que mais gosta, Perec explicita essa operação através da qual ele pode criar sua própria comunidade, dando, através da literatura, sentido a sua existência: "releio os livros que amo e amo os livros que releio, e toda vez com

${ }^{11}$ Destinatário do testemunho. 
a mesma alegria (...): a de uma cumplicidade, de uma conivência, ou, ainda mais além, a de um parentesco enfim redescoberto" (PEREC, 1975: 195). A ficção de $W$ permite, então, ao escritor realizar aquilo que Des Forêts nos diz a respeito da busca identitária: "[r]epresentar-se outro em relação ao que fomos para tornar-se aquele que somos procede de uma aspiração idêntica - encontrar sua verdade própria (...).” (DES FORÊTS, 1993: 22). Em W ou le souvenir d'enfance, é essa "verdade própria" que coloca as cinzas em movimento, engendrando os traços dessa memória-montagem, na qual o sujeito pode, por meio do entrelaçamento entre vida e ficção, apropriar-se de seu passado ao inventar seu próprio destino.

\section{Referências bibliográficas}

ANTELME, Robert. L'espèce humaine. Paris: Gallimard, 1978. (Coll. "Tell”)

BIRMAN, Joël. "Écriture et psychanalyse: Derrida, lecteur de Freud". Figures de la psychanalyse, 2007/1 n. 15: 215.

CREPON, Marc. "Sigmund parle-t-il en Derrida?". Magazine littéraire, n. 544, jun., 2014: 58.

DERRIDA, Jacques. "Il n'y a pas de narcissisme". In: Points de suspension. Paris: Éditions Galilée, 1992: 222.

"Freud et la scène de l'écriture". In: DELEUZE, Gilles. Différence et répétition. Paris: Éditions du Seuil, 1967: 293-340. (Coll. Tel Quel)

DES FORETS, Louis-René. Face à l'immémorable. Paris: Fata Morgana, 1993: 20-21. DIDI-HUBERMAN, Georges. Blancs soucis. Paris: Les Éditions de Minuit, 2013: 104. PEREC, Georges. W ou le souvenir d'enfance. Paris: Danoël, 1975.

. L.G: une aventure des années soixante. Paris: Seuil, 1992. (Coll. "Librairie du XX siècle")

. Ellis Island. Paris: Hachette, 1995: 56. (Coll. P.O.L.)

"La disparition". In: Romans et récits. Paris: Le livre de Poche, 2002. (Coll.

"La Pochotèque")

Entretiens et conférences II. Paris: Joseph K., 2003: 50.

RANCIÈRE, Jacques. "La fiction de mémoire". Trafic, n. 29, 1999: 36-47.

Rodrigo Ielpo é doutor em Letras (Literaturas de Língua Francesa e História e Semiologia do texto e da imagem) em regime de cotutela pela Universidade Federal do Rio de Janeiro e Universidade de Paris 7 (2010). Fez estágios de pós-doutorado em Teoria Literária na Unicamp e na Universidade de Paris 7, ambos com bolsa FAPESP. Atualmente, é professor de Literatura Francesa da Universidade Federal do Rio de Janeiro, atuando nas seguintes áreas: literatura francesa moderna e contemporânea, literatura e processos de subjetivação, literatura e história, teoria literária francesa. E-mail: rodrigoielpo@gmail.com. 